\title{
AC 2012-3961: REVISITING A LIBERAL ACTIVITY IN A COLLEGE OF ENGINEERING ENGINEERS AS POETS 10 YEARS LATER
}

Mr. Craig J. Gunn, Michigan State University

Craig Gunn is the Director of the Communication Program in the Department of Mechanical Engineering at Michigan State University. His duties include the integration of communication skill activity into all courses within the mechanical engineering program, including overseas experiences. He works closely with the Cooperative Engineering Education Division of the College of Engineering to monitor the communication skills of students who co-op during their college years. He is currently the Editor of the CEED Newsbriefs and is co-author of a number of textbooks focusing on engineering freshmen orientation. 


\title{
Revisiting a Liberal Activity in a College of Engineering Engineers as Poets 10 Years later
}

\begin{abstract}
Ten years ago many people thought for a variety of reasons that encouraging engineers to write poetry in a college of engineering was a foolish endeavor. These naysayers proclaimed the lack of any value in the pursuit, the foolishness of any endeavor that made use of the weaker rightbrained skills (Everyone knew that soft skills were worthless!) and a complete trust in the fact that engineers were never intended to be creative or in any way able to write anything that bordered on the creative arts. Over these past years, the College of Engineering at Michigan State University has endeavored to open up the flood gates and let the creative juices flow. Ten years have passed and many of the naysayers have slipped away into the shadows, mumbling about their distrust of "soft skills" but unable to completely disregard the quality and quantity of the creative works that have been produced by every level of engineer: student, faculty, and staff (and now elementary, middle, and high school students).
\end{abstract}

\section{Introduction}

A poetry forum was created eleven years ago to simply provide a place where engineering students could express themselves in something other than technical presentation. It was never intended to be any part of an assignment or an activity that could be interpreted as something required of anyone in the college. It was purely for fun and investigation. For these ten years we have encouraged those who might like to participate to do so. We have spread the word outside the college to elementary, junior high, and high school students and have found students interested in taking a stab at a few lines of poetry. While still focusing our efforts on the engineering writers, we will never turn aside writers from other majors who would like to participate. The preliminary assessment we have done looks at how the students find their own poetry writing and the enjoyment that they might get from participating. There are many individuals who will never gain a desire to write poetry; but for those who do, providing this venue makes the effort worthwhile. As other directions of writing are investigated, hopefully more students will be drawn into other activities that expand their ideas on communication.

ABET's requirements for accreditation since 2000 give a clear indication that written communication is of tantamount importance in the education of undergraduate engineers. It is interesting to note that previous to EC 2000, communication in all its forms did not merit more than a few lines hidden away in the ABET document. With its newly gained prominence, educators are scrambling to make sure that their programs contain the right blend of technical and communication skill training. While this training focuses on adequate lab reports, grammatical correctness, and suitable vocabulary, there are other ways that might help to interest students in the communication needed in their profession. As a means to initiate more communication within the College of Engineering at Michigan State University, our collegewide poetry contest was instituted in 2000 to coincide with Engineering Week. The prime motivation behind the contest was to show the creative talent of the engineering students, but it also served a needed purpose of providing a visible validation for their sometimes-secretive writing activities. 


\section{The Poetry Forum}

The Poetry Forum as it is called has allowed a segment of the engineering population a chance to express ideas in ways that may not have been readily condoned in previous times. On the other hand, it has also returned other individuals to a time when they were encouraged to try their hand at writing "outside the box." As one elderly faculty member commented, "When I first started teaching, I was at an engineering school that almost required that everyone from the president to the custodians produce poetry during the year.” Therefore the spectrum was wide open to encourage writing that might just pique the interest of certain student, faculty, and staff. And it has done just that. Poetry writing for those interested individuals has provided an avenue for communication.

When an earlier paper began with the following quotation, "Variety's the spice of life, that gives it its flavor," it echoed a feeling that stifling the creativity of any group of individuals is not productive. Allowing these individuals to range across various types of communication is not only good for engineers expressing themselves but for the production they produce in their engineering activities. These lines in "The Task, I" by William Cowper (English poet 17311800) still reflect an attitude over two hundred later that must he fostered in the minds of engineers. No man is an island, and no field of study can divorce itself from the activities, interests, and positive reinforcement of divergent areas of instruction. Students who become embroiled in the quest for a degree in any of the engineering areas can quickly close the doors to many of the more liberal pursuits. The feeling exists that any time spent on "non-engineering" pursuits is not beneficial to the career. Efforts to continually foster varieties of communication experiences should be included in the educational structure of every engineer with ample connections to the world of the humanities.

Too many engineers go through their college or university careers unaware that many of their peers studying fluids, circuits, controls, composites, or calculus have vast experience in the liberal arts. These talents and interests lie hidden while the technical courses are taken and technical knowledge is gained. It is important to the rounded education of engineers that an effort be made to bring to light the liberal interests of engineers. Age-old stereotypes that influence the way that engineers perceive themselves need to be investigated, modified, and in many cases destroyed.

When the science revolution took place in the 1700s, the movement to divorce the scientific world from the arts was loudly applauded by liberal studies activists. Science was trying to carve its place in the world and, therefore, had other issues to consume its time, Complaints over the past decades have reflected upon this separation of disciplines. We have been deluged with "right brain, left brain" concerns, with cries that "engineers cannot communicate", and with the whole smokescreen of what is perceived to be the "stereotypical engineer." We can decry these attitudes, but many are ingrained into the society in which we live and work. While the public's perception of engineers may require a vast reeducation, it is with the engineers that the first steps must be taken to change the incorrect vision.

The comments made here will not deal with the vast battle lines that involve the world outside of engineering. To cover that issue would take much greater space than can be allowed in this work. The area that will be investigated approaches the issue from the inside by targeting the engineering faculty, support staff, and students. 
No visible change can take place in the attitudes of people if interest and a willingness to discuss are not present. In order for the attitudes of the world to change, engineers must first believe that there is no wall between the sciences and the humanities. As engineers grow in their realization that the humanities do hold an important place in their lives then the word will reach out to the masses of people outside the engineering disciplines. Interested parties in every engineering department should be functioning as catalysts to the thoughts of groups fostering liberal education within engineering disciplines. They should he working to make every student, staff, and faculty member aware of the liberal education interests of everyone connected to engineering.

An important element of the effort in fostering poetry writing is a question of value to the engineer, him or herself. Found on http://blogaboutwriting.com/2009/04/4-benefits-of-poetry/ ${ }^{1}$ is a concise set of reason that speak to the writing and reading of poetry and its importance in the life of the technical writing engineer who needs both writing activity and a vitality that comes from a variety of writing experiences.

1. Poetry helps you to know things more fully. When I turn things over to put them into verse, I often find that I have to shift my perspective, usually to see more closely I passed beyond the big things moving closer and wider to see a broader picture than had originally come to mind.

2. Poetry commands your attention. There's reading and then there's reading. You can't skim a poem and get what the writer sets forth for you, which is not the whole of it. The rest is filled in with a big part of who you are. Really, when you think about it, anything you can comprehend is understood from the context or frame of reference you have. Poems leave a little more room for you in the verses.

3. Poetry can sustain good conversation. Two people can read the same poem and get very different things out of it. I've had some really interesting conversations around poetry. In fact, one of the poems I wrote called What Could I Lose brought a woman to tears, whereas it made me smile when I wrote it. After the reading she spoke with me and made me understand where the poem transported her.

4. Poetry writing asks you to dig deeper. It feels like Twitter sometimes. Poetry makes no restrictions on the number of characters you use, or the words. However, you work to tell your story, to convey your thoughts and emotions, reflections and opinions. And you do this in verse form instead of prose.

One can see in the above how the discussion of the benefits of poetry can be made to a group of engineers. Expressing oneself, thinking about the words, and molding the words one uses to convey meaning can easily start with poetry and lead to better technical production.

One finds a very interesting situation when one approaches the issue of the humanities and its connection to engineering. The stereotypical vision of the engineer is rampant in both the engineering community and the world outside engineering. It is enlightening to note, though, that the stereotype is only a superficial belief among the vast majority of engineers. It appears to be necessary for many to foster this belief in order to keep the engineering area pure from liberal notions. The importance of the technical education is somehow enhanced by the fact that it is not connected to the arts and letters curriculum. When one sits down with engineers in a nonthreatening environment where true feelings can be expressed, a different impression is 
expressed. Students begin to speak about the instruments that they play and the particular level of competence that they have achieved in the musical world. When discovered working on the computer, students will blush when they speak of the poetry that they write, the most recent play that has been penned, or the latest collection of short stories that have been produced. In many cases, this admission seems to be something that should he left hidden in a veil of secrecy. Students never seem ready to admit to a sharing of liberal ideas, needs, and wants. This desire to submerge these interests in areas other than engineering demonstrates the need to revitalize the education of future engineers.

All the above activities may be of interest to those who believe that elements of the humanities are a vital part of an engineer's education. The problem exists when we approach the typical student body and inform it that the humanities should be investigated, utilized, and made a part of an engineer's life. Here the necessity is to make a case for the unification of the technical and liberal sides to education. The intricacy of musical pieces, the knowledge that can be gained from working carefully through a text, or the meticulous effort that needs to taken in painting a work of art are activities that complement the direction that engineers commonly follow in gaining their knowledge. Engineers are meticulous. They strive for clarity and conciseness, and their research requires exacting pursuit until every contingency is addressed. The creative mind presents these same requirements. As engineers delve into the world of liberal arts they will find the connections that unify the two areas of study. The catalyst that can begin this process is as close as the department in which they study. Conversation leads to discussion. Discussion can open wide the doors. Here we enter the world of poetry and its place in the College of Engineering at Michigan State University.

In the first year of the poetry contest, approximately 50 students, faculty, and staff submitted almost 100 poetical works that covered engineering themes and the more liberal areas of love, friendship, and heartache. During a three-week period, the submissions flowed freely and the excitement grew in the college. Some awaited the announcement of winners, and some chose to await the end of the contest to see if engineers could really produce quality material. It did not take long for the results to show both the creativity and the depth of ability in the engineers. The following poem by Joe Kramer shows a fun loving ability to investigate the language and give it life.

\section{My Poem Would Eat Nothing}

Like a stubborn little child acquiring new tastes.

I try to feed him metaphors, verbs, nouns, but they all oozed out. How about a fresh batch of adjectives?

No.

Well I am running out of options.

How about some pro-nouns?

Everybody loves pro-nouns.

No, there they go dribbling off the page and onto the floor. 
I have no idea what to try next, but maybe you will be ready tomorrow.

Here Julie Richards a mechanical engineering student opens her heart in a poem with no title, while Steve Miller presents a more lighthearted presentation.

Having children scares her.

Terrifies her.

She trembles at the thought.

Dirty clothes and faces and diapers

And cuts and bruises and scrapes

And pushing and sweating and nightmares

She doesn't want any of this.

But she must have it.

Her body tells her

And her head tells her

And husbands and

Mothers and sisters and fathers

And the neighbors that live

Behind them in the odd blue house

That is strangely intriguing.

Determination over comes her.

Drives her.

And suddenly it happens everywhere.

In the bedroom and the dining room

And in kitchens and bathrooms

And in the back of the car

They borrowed to drive down to

Connecticut to visit friends

They haven't seen

In ages.

So then it happens.

The plus stares at her.

She sobs.

Everybody is calling and

Cards and flowers and balloons

And presents that are strangely intriguing

Even though they are lurid in their pinks' and blues' and yellows.' She becomes everything

All at once.

And all against her will. 


\title{
Extreme Engineering
}

\author{
The Art of Engineering \\ Taken to the Extreme \\ With Math Beyond \\ What Newton Dreamed \\ Reimann Sums, Taylor Series, \\ And Vectors Galoo \\ Yikes what will all this come to? \\ No artist is solo - \\ We work in teams \\ Building Slinkys and Spacecraft \\ There isn't anything that we can't do! \\ Breaking barriers and withstanding failure we \\ Change the world with products and plasma goo! \\ Bringing our dreams past all known extremes.
}

In 2002, the number of entrants increased to over 75 with an added excitement that showed that students were not only interested in submitting work but experiencing what others had written. The range of work increased and the creativity continued to grow. It was especially interesting to see students reading those works that were deemed winners in the contest when they were displayed in the lobby of the Engineering Building. There was a quiet reserve in the lobby turned reading room. Some students were even heard to ask other students "to quiet down so they could truly enjoy the reading." Poetry had become something that was not the property of those liberal education majors on the other side of campus. Poetry was a part of engineering as much as math and science. The depth of understanding and ability to present ideas improved.

\section{Nothing but a Yellow Pepper Scott Douglas}

Once again I have passed on the opportunity to cook In exchange for valuable time in this place

As I walk down the halls my eyes scan the papers that adorn the walls

They all seem the same

Roommates wanted, car for sale...... but wait

Like a needle in the haystack there lies an interesting proposal

"Come to the meeting for Free pizza"

It immediately draws my attention

My mind races with a million questions

Is this a trap? Who are these sharks luring me in?

Will I survive their Jedi mind tricks to make me join their secret society?

If I go how many slices will I get and will it be worth it?

This is were my engineering skills have prepared me

I grab for my TI-86 and start to calculate

Checking a standard distribution curve I find that the average meeting has 50 slices

Not bad considering the average person consumes 2.4 slices per meeting

Total number in attendance $=12$ members +10 attendees +1 straggler 
After some Venn Diagrams and Eigenvectors I figure I can get $32.99 \mathrm{in}^{2}$ worth of pizza

My heart begins to race and my mouth waters

I desperately search for a room number on the colored paper

As soon as I see it I am off

I am almost there when I screech to a halt

I haven't taken into account the type of pizza!

Considering this group's taste I figure they will go cheap

I quickly pull out my calculations again and continue

The pizza will be thinner than paper so my consumption volume will be roughly 8.25 in $^{3}$

This may not be worth it

After some minutes of decisive thinking it hits me

I quickly draw a Design Matrix and give my problem the appropriate weighting factors

Highest score wins here so it's all or nothin'

Should I stay or should I go?

With a score of 92.5 to 67 the winner is clear

I run to the meeting and try to sneak in unnoticed

All eyes are on me but I don't care I'm hungry

I walk over to the pizza boxes for my 2.4 slices

I open the top

Nothing but a yellow pepper

\section{The Ph.D. Student's Dilemma Sean Davis}

A grad student was running some tests, the results of which were leaving him vexed.

The thermal diffusivity

of bovine artery

was higher than those cited in texts!

He checked over each boundary condition.

Locating error was his personal mission.

The device was realigned

and the model was redesigned;

still the aorta showed high heat transmission.

Former students and peers were contacted

and suggestions were subsequently enacted.

To account for some heat

transmitted thru the meat

at this rate which is quicker than expected.

Still the data ran a little bit high

The grad student thought he would cry!

No amount of statistics

short of something sadistic

would reduce the error in squared-chi. 
What is the cause of this horrible lament

which caused the alpha to ascent?

It was arteriosclerosis,

which caused tissue necrosis,

no wonder that cow sported a stent!

\section{Everything Changes}

Katie Adams

Teardrops splatter and

pictures fade away.

Memories grow dim, love switches names.

Everything changes

as life passes by.

Candles flicker

in the face of time.

From 2002 to 2011, the number of students, faculty, staff, and individuals from the community increased and decreased as the interest of those individuals peaked or waned. Never was there considered a removal of the poetry forum from the calendar simply because the numbers of submissions were not increasing markedly. Some individuals submitted once, never to be heard from again, while others made an effort to submit every year to the forum. During the time, individuals came and went as their interest in the activity showed. What was learned from this was that there were a large number of individuals who felt that they wanted to try the writing of poetry with no pressure and see if it was something that they wanted to continue. Here we learned a lot from the participants. Some simply said that they did it, "as a joke." They "wanted to play with the words and see where they might lead." It was a one-time thing that might or might not return to their liking in the future. Others commented that they had, "been forced to write poetry in the past, but might like to see what it was like with no coercion!” The ability to allow students and others to let their hair down and write in a manner that was not a regular staple of their communication diet was "refreshing" to these individuals. They existed on formal lab reports and being able to produce text that did not have to adhere to the rigors of technical text was a comfortable avenue for exploration.

Roses are red.

Violets are blue.

I have a machete.

Get in my van!

The above poem may not meet all the requirements set by the formal writers of poetry, but it definitely takes the reader into another sphere of understanding and interest. One can laugh at the words but can also think about what else is not said in the text. It gets the reader to ponder, evaluate, and perhaps understand. This is where we wanted the forum to proceed. It needed to be a place where students were allowed to simply write. And with this there were critics who said that it should be more structured, "more poetic," and less creative. We found that interesting because when looking at the writing of poetry we wanted it to be as structured only as much as the poet wanted, less traditionally poetic, and fantastically creative. We wanted it out of the box, delving into every corner to which the writer felt he or she wanted to take the experience. 
From 2002 to the present, poetry has flourished in the College of Engineering at Michigan State University. It has wound itself around themes that are ridiculous and playful to serious and intensely personal. The writers have found another voice for their inner selves and they have commented that their efforts have given them a greater outlook on the power of words and the need for their own engineering text to be as closely understood and perfected as any poem that they write. They have said it in so many words, but Michael Maxwell http://michaellmaxwell.hubpages.com/hub/TheBenefits-of-Writing-Poetry ${ }^{2}$ gives us his simple sentence, "The benefits of Poetry are communication, self-expression, differentiation, unification, therapy, and self-assertion.”

When I look back I begin to miss,

The late nights by the fire, It was then I made my wish, Hoping it would never end.

When I look back I begin to wonder, How I made all those mistakes, I would have changed them all, But it was already too late.

When I think about my life, Wishing it would never change, Those times always seemed just right, But only the memories remain.

\section{Stephen Jurewicz}

Stephen Jurewicz probably couldn't convey his feelings as well in prose as he does in the few short lines above. He is communicating in an area outside of engineering and yet important to engineering because he is practicing the art of creating text, choosing words, and experimenting with ideas that can captivate and excite his readers to think of things they themselves can express if only they try. We have the effort to do the same.

When we read the words of Stephanie Moore in "Making your poetry Better," http://writinghood.com/style/how-to/creative-writing-101-the-benefits-of-developing-yourpoetic-skills/\#ixzz1jCYISkm0 ${ }^{3}$ we can see how we can speak to engineers about the importance of simply making an effort to write poetry and how the effort will benefit their other writing assignments.

Communicating your heart takes effort. Think how often spoken words fall short! Now tell me, poets: How can you communicate your heart when you confuse your readers with misused words and obscure references? How can YOU communicate in YOUR voice when you sound like every other Hallmark card and angst-ridden rock song out there? How will you get your reader to respect your words if YOU don't respect your words enough to choose them carefully? I leave you with this: Webster's definition of the word *art*: skill acquired by experience, study, or observation (the art of making friends) , or an occupation requiring knowledge or skill. All of you have what it takes to write poetry. It's no secret: work." 
Poetry allows engineers to produce text that is outside the normal technical production. These engineers can let their creative juices flow within both technical and non-technical areas, experimenting with language and structure. Poetry allows the engineer an avenue for expression in a very technical existence.

And from John C. Mannone "Collateral Benefit: The Impact of Poetry on Prose Writing (and Vice Versa)" 4

How can poetry help your prose?

- Tightness of language is a hallmark of poetry, even in conversational and anecdotal forms. Language manipulation is a trait of poetry that can greatly benefit prose.

- Metaphor, simile, imagery and other metaphorical language help immerse the reader into the world painted by words.

- Rhythm, best noted by reading the story aloud, is coveted not only for smooth reading, which will advance the story without stumbling, but also for setting the pace (which should vary) by "alerting the ear” to optimum sentence lengths and punctuation.

- Internal rhymes and effective repetitions provide echoes in language, which give body to the story in the same way rich harmonics affect the sound of fundamental chords. This affects things like mood, too, and can help deliver poignancy, pathos, or even humor.

While directed at areas seemingly outside the realm of technical writing, the above allows an engineer to think about how text works, flows, and captures the mind of the reader. The adventure of writing poetry can help to affect the overall feeling that one takes into mind as he or she writes text.

\section{Future Liberal Activities in Creative Endeavors}

It is important to realize that not everyone feels the need to write poetry or the desire to delve into other avenues of creative effort. Time to become involved may not be clear to someone who is overly burdened with engineering requirements. This does not mean one should stop making every effort to provide ways to bring engineers into those "other" forms of writing. Efforts are in the works to create a college of engineering poetry presence on the web, the creation of poetry books containing engineering poetry from Michigan State University's College of Engineering, continued novel writing activities, creative activities in the college machine shop with sculpture and mobiles, and evenings of painting. These and many other as yet unnamed activities will hopefully keep the engineer alive in the liberal arts, arts that allow that engineer to break out of the box and see how working in areas other than engineering can be beneficial to one's career.

It was felt that it was necessary to ask very pointed and relatively simple questions about poetry in general that might lead to a different approach to gaining increased poetry writing acceptance in the College of Engineering at MSU. Questions asked of random students about writing and writers who participated in the yearly Poetry Forum. In our first efforts we were simply concerned with general Yes and No and Maybe answers to start the conversation going. While the same people were not surveyed over all the surveys, we feel it is start to addressing very 
simple perceptions about the writing of poetry by engineers. Approximately 75 students were polled on their feelings about poetry on any one of the surveys with the following results.

1. Do you see a need to expand your arts and letters experience?

\begin{tabular}{|l|l|l|l|l|}
\hline No & & Maybe & & Yes \\
\hline 60 & & 30 & & 10 \\
\hline
\end{tabular}

2. Do you find writing poetry relaxing?

\begin{tabular}{|l|l|l|l|l|}
\hline No & & Maybe & & Yes \\
\hline 40 & & 45 & & 15 \\
\hline
\end{tabular}

3. Do you find that the writing of poetry makes you think more about your word choice and techniques of writing?

\begin{tabular}{|l|l|l|l|l|}
\hline No & & Maybe & & Yes \\
\hline 70 & & 25 & & 5 \\
\hline
\end{tabular}

4. Do you see yourself writing poetry as a general practice?

\begin{tabular}{|l|l|l|l|l|}
\hline No & & Maybe & & Yes \\
\hline 90 & & 5 & & 5 \\
\hline
\end{tabular}

5. Will you submit poetry to future forums in the college?

\begin{tabular}{|l|l|l|l|l|}
\hline No & & Maybe & & Yes \\
\hline 40 & & 40 & & 20 \\
\hline
\end{tabular}


1. Do you like poetry?

\begin{tabular}{|l|l|l|l|l|}
\hline No & & Maybe & & Yes \\
\hline 60 & & 20 & & 20 \\
\hline
\end{tabular}

2. Do you read poetry on a regular basis?

\begin{tabular}{|l|l|l|l|l|}
\hline No & & Maybe & & Yes \\
\hline 95 & & & & 5 \\
\hline
\end{tabular}

3. Do you listen to song lyrics?

\begin{tabular}{|l|l|l|l|l|}
\hline No & & Maybe & & Yes \\
\hline 10 & & 10 & & 80 \\
\hline
\end{tabular}

1. Does writing poetry have any effect on your regular writing assignment?

\begin{tabular}{|l|l|l|l|l|}
\hline No & & Maybe & & Yes \\
\hline 85 & & 5 & & 10 \\
\hline
\end{tabular}

2. Do you feel constrained when asked to write poetry?

\begin{tabular}{|l|l|l|l|l|}
\hline No & & Maybe & & Yes \\
\hline 10 & & 30 & & 60 \\
\hline
\end{tabular}

3. Would you write poetry if you have a template to follow just to get you started?

\begin{tabular}{|l|l|l|l|l|}
\hline No & & Maybe & & Yes \\
\hline
\end{tabular}




\begin{tabular}{|l|l|l|l|l|}
\hline 30 & & 40 & & 30 \\
\hline
\end{tabular}

From each of these surveys we realized that there is a core of students who truly find writing, and especially poetry writing, to be of value for their own personal reasons. There is also a segment of the engineering population who might be enticed or more strongly encouraged to make an effort to write out of the technical box. We will now begin to survey with more vigor on ways that we can find the students themselves telling us to encourage them to write a few short lines of poetry.

\section{Conclusions}

Writing, speaking, thinking, and listening in areas other than engineering are activities that can easily be sponsored and perpetuated in engineering departments. They require little outlay of expenses. They allow writing to be practiced by engineers who actually like the adventure of writing something other than a technical report. Poetry forums provide a means to open up such avenues for communication. Students made aware of the need to expose their liberal talents and interests to their fellow engineers will bring to engineering a whole new area of creativity, creativity that is at the heart of all true engineers. Faculty and staff members should utilize any means possible to draw connections between engineering and the liberal arts. At the simplest level it is an awareness issue. As more individuals are made aware of the mutual interests of their colleagues, the separation of the liberal arts and the sciences will shrink. With this shrinkage will come a greater awareness on the part of the rest of the world and with it a firmer commitment to see the whole person and not the stereotype.

\section{References}

1. http://blogaboutwriting.com/2009/04/4-benefits-of-poetry/

2. http://michaellmaxwell.hubpages.com/hub/The-Benefits-of-Writing-Poetry

3.http://writinghood.com/style/how-to/creative-writing-101-the-benefits-of-developing-yourpoetic-skills/\#ixzz1jCYISkm0

4. http://jcmannone.wordpress.com/ 